\title{
The Dental Safety Profile of High-Dose Radioiodine Therapy for Thyroid Cancer: Long-Term Results of a Longitudinal Cohort Study
}

\author{
Martin A. Walter*1,2, Christian P. Turtschi*1,2, Christian Schindler ${ }^{3}$, Peter Minnig ${ }^{4}$, Jan Müller-Brand ${ }^{1}$, and Beat Müller ${ }^{2}$ \\ ${ }^{I}$ Institute of Nuclear Medicine, University Hospital Basel, Basel, Switzerland; ${ }^{2}$ Clinic of Endocrinology, University Hospital Basel, \\ Basel, Switzerland; ${ }^{3}$ Institute of Social and Preventive Medicine, University of Basel, Basel, Switzerland; and ${ }^{4}$ Institute of \\ Public Dental Health, Basel, Switzerland
}

The long-term dental safety profile of high-dose radioiodine therapy remained elusive despite more than 6 decades of clinical use. Methods: In a cohort study, we investigated the incidence of sialadenitis, xerostomia, caries, and tooth extractions after high-dose radioiodine therapy for differentiated thyroid cancer and explored risk factors by multiple regression models. Results: One hundred seventy-six participants were recruited (median follow-up, $6.6 \mathrm{y}$; range, 1.1-32.6 y; patient-years: 8,472 before and 1,421 after radioiodine therapy). Scintigraphic salivary gland uptake during radioiodine treatment predicted development of sialadenitis (odds ratio: 1.31 [1.05-1.63], $P=0.015$ ) and xerostomia (odds ratio: 1.58 [1.16-2.16], $P=0.004$ ). The caries risk increased by postradioiodine xerostomia (\% increase: 98.8 [26.5-212], $P=0.003$ ). The long-term risk for postradioiodine tooth extractions increased with increasing cumulative radioiodine activities (\% increase [per gigabequerel]: 8.14 $[1.07,15.7], P=0.02)$. Conclusion: High-dose radioiodine treatment can impair the long-term dental health, depending on the cumulative radioiodine activity and individual salivary gland radioiodine uptake.

J Nucl Med 2007; 48:1620-1625

DOI: 10.2967/jnumed.107.042192

$\mathbf{R}$ adioiodine is routinely used in the treatment of differentiated thyroid cancer $(1,2)$. It is accumulated in thyroid tissue by sodium iodide symporters and exerts cytotoxic effects by $\beta$-irradiation. Similar sodium iodide symporters in salivary glands (3) lead to radioiodine uptake comparable to thyroid tissue (4). Salivary glands are highly radiosensitive (5) and, accordingly, sialadenitis and xerostomia are the most frequent adverse events of high-dose radioiodine therapy (6). The incidence of sialadenitis after high-dose radioiodine therapy is about $30 \%(7-9)$, and consequent reduced salivary

Received Mar. 28, 2007; revision accepted Jul. 24, 2007.

For correspondence or reprints contact: Martin A. Walter, MD, Institute of Nuclear Medicine and Division of Endocrinology, University Hospital, Petersgraben 4, CH-4031 Basel, Switzerland.

E-mail: m.a.walter@gmx.net

${ }^{*}$ Contributed equally to this work.

COPYRIGHT @ 2007 by the Society of Nuclear Medicine, Inc. gland function (10) and altered saliva composition (11) develop in all patients. Clinically relevant xerostomia with dry mouth, taste loss, and swallowing difficulties arises in $11 \%-$ $44 \%(7-9)$.

Saliva has vital functions in maintaining oral health. Therefore, xerostomia not only impairs quality of life permanently but may also increase the risk of caries and tooth extractions $(12,13)$. Nevertheless, despite more than 6 decades of radioiodine therapy for thyroid cancer, studies on long-term oral adverse events are lacking (14).

In the present study, we investigated the influence of high-dose radioiodine therapy on the long-term oral health.

\section{MATERIALS AND METHODS}

The study was designed and performed compliant with Good Clinical Practice, Swiss drug laws, and the Declaration of Helsinki. It was approved by the local ethics committee and registered (ClinicalTrials.gov Identifier: NCT00439478). Written informed consent was obtained; all endpoints were predefined.

\section{Patients}

Between January 2005 and January 2006, patients were recruited from our thyroid cancer registry, instituted in 1972. Inclusion criteria were histologically confirmed differentiated thyroid cancer, status after total thyroidectomy and radioiodine treatment, follow-up by a board-certified dentist, $\geq 1$ y follow-up after radioiodine therapy.

\section{Treatment}

Before radioiodine therapy, all participants had received a standardized baseline clinical assessment. Exclusion criteria for radioiodine therapy were anaplastic thyroid cancer, incontinence, pregnancy, breast feeding, and severe concomitant illness. Six to 8 and 14-16 wk after thyroidectomy, 2 cycles of ${ }^{131}$ I therapy were performed. Further cycles were scheduled in case of tumor persistence or recurrence. ${ }^{131} \mathrm{I}$ was administered orally and patients were hospitalized for $3 \mathrm{~d}$.

\section{Imaging}

Scans were obtained $5 \mathrm{~d}$ after ${ }^{131} \mathrm{I}$ application with a $\gamma$-camera (parallel-hole, medium-energy, general-purpose collimator; windows center, 284-keV peak; window width, 20\%). The ${ }^{131}$ I uptake in the parotid and submandibular glands was visually scored by 2 
board-certified nuclear medicine physicians, who were unaware of clinical data, using a 2 -point scale: $0=$ no uptake; $1=$ visible uptake (Fig. 1). A ${ }^{131}$ I uptake score was calculated by summing the uptake grades of all 4 examined salivary glands.

\section{Follow-up}

All participants were treated with thyroid hormone to suppress thyroid-stimulating hormone secretion and systematically underwent a yearly follow-up after radioiodine therapy. The standardized follow-up procedure included the participant's history, physical examination, measurement of serum thyroglobulin levels, and imaging procedures.

Participants were also systematically assessed with regard to general dental care (frequency of oral hygiene, use of dental floss, fluorine, fluoride rails, fluoride gel, toothpicks, mouth rinsing, frequency of consultations at the dentist, and professional dental care), dental status before or after radioiodine therapy (dental pain, incidence of caries and calculus, tooth extractions), gingival status before or after radioiodine therapy (gingival inflammation, gingival bleeding), and salivary glands status (symptoms of sialadenitis, xerostomia, need for saliva replacement, alteration of taste and diet). The participants' dentists remained unaware of the cumulative administered radioiodine activity and were asked for data on dental status before or after radioiodine therapy (incidence of caries and calculus, tooth extractions), gingival status before or after radioiodine therapy (gingival inflammation, gingival bleeding), and salivary glands status (xerostomia, indications for saliva replacement).

\section{Endpoints}

Endpoints were sialadenitis and xerostomia as reported by patients and caries and tooth extraction as reported by the patients' dentist, graded according to the Common Terminology Criteria for Adverse Events (CTCAE, http://ctep.cancer.gov/forms/CTCAEv3. pdf) of the National Cancer Institute.

\section{Statistical Analysis}

The endpoint xerostomia was analyzed using logistic regression. Sialadenitis was assumed to follow a binomial distribution with up to 4 possible events and covariate-dependent individual event probability $P$; accordingly, binomial regression with adjustment for overdispersion was used to analyze the influence of different predictor variables on sialadenitis. The numbers of caries sites and tooth extractions after radioiodine therapy were analyzed using Poisson regression. These 2 outcomes require time to develop, and their expected values depend on the length of the follow-up period, which was considered by treating its natural logarithm as an offset variable in the Poisson regression models. Correction for

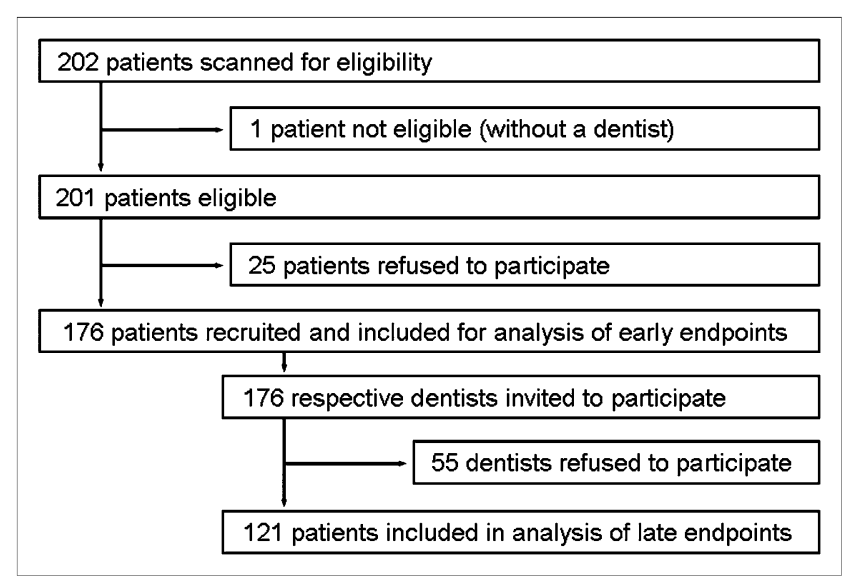

FIGURE 2. Trial flow.

overdispersion was based on Pearson residuals. For quantitative covariates, we assessed whether linear terms alone sufficiently described their association with the outcome variable or whether the model was improved by introducing their square or third power. In this case, the covariate was categorized. Sensitivity analyses for all endpoints were performed according to available versus nonavailable intratherapeutic ${ }^{131} \mathrm{I}$ scans and available versus nonavailable data on caries before radioiodine therapy. Discrete variables are summarized by counts (percentages) and continuous variables are summarized by their median (range). A $P$ value of $<0.05$ was considered to be significant. Data were analyzed using SAS 9.1 (SAS Institute Inc.) and Statistica V.6.0 (StatSoft, Inc.).

\section{RESULTS}

\section{Patients}

At January 1, 2005, our register comprised 202 patients, treated 1972-2004. One patient had no dentist; 201 patients were eligible (Fig. 2). One-hundred seventy-six patients (87.6\%) were recruited (Table 1). Twenty-five patients refused participation; their baseline criteria did not significantly differ from those of the recruited patients (data not shown). Eighty dentists cooperated and contributed data on 121 of $176(68.8 \%)$ participants.

\section{Treatment}

The 176 participants had undergone a median number of 2 (range, 1-6) cycles with a median cumulative radioiodine
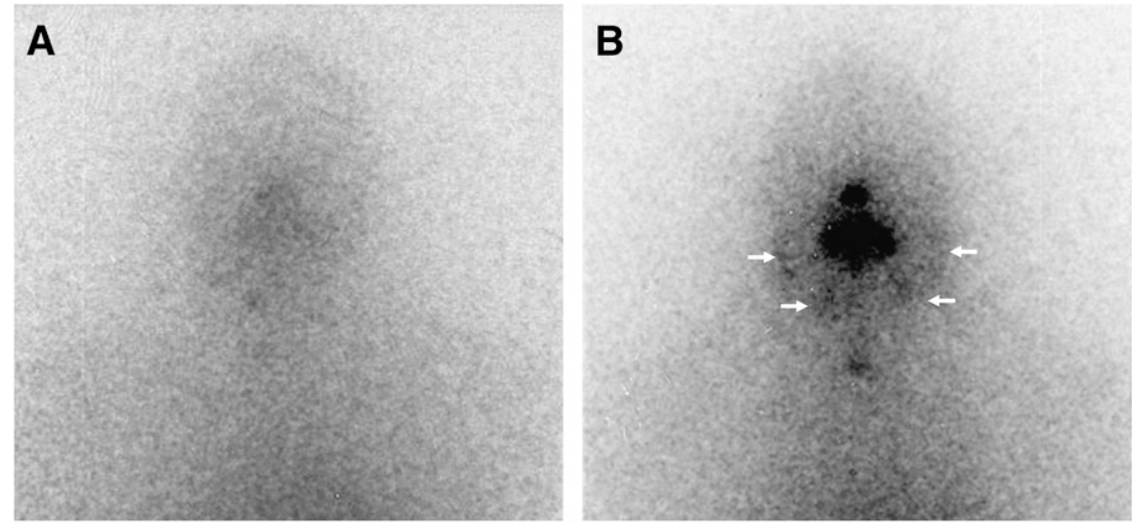

FIGURE 1. Salivary gland ${ }^{131}$ I uptake: (A) Grade 0 (no visible uptake). (B) grade 1 (visible uptake, arrows). 
TABLE 1

Participants' Baseline Criteria $(n=176)$

\begin{tabular}{|c|c|c|}
\hline Characteristic & Finding & Value \\
\hline Sex & $\begin{array}{l}\text { Female } \\
\text { Male }\end{array}$ & $\begin{array}{l}126(71.6 \%) \\
50(28.4 \%)\end{array}$ \\
\hline Age at radioiodine treatment $(\mathrm{y})$ & $\begin{array}{l}\text { Median } \\
\text { Range }\end{array}$ & $\begin{array}{l}48.4 \\
17.6-86.3\end{array}$ \\
\hline Thyroid cancer entity & $\begin{array}{l}\text { Papillary } \\
\text { Follicular } \\
\text { Unspecified* }^{*}\end{array}$ & $\begin{array}{l}110(62.5 \%) \\
65(36.9 \%) \\
1(0.6 \%)\end{array}$ \\
\hline TNM stage & $\begin{array}{l}\text { T1, T2, T3, T4 } \\
\text { Tx } \\
\text { N0, N1, N2 } \\
\text { Nx } \\
\text { M0, M1 } \\
\text { Mx }\end{array}$ & $\begin{array}{l}22(12.5 \%), 89(50.6 \%), 24(13.6 \%), 21(11.9 \%) \\
20(11.4 \%) \\
70(39.8 \%), 29(16.5 \%), 3(1.7 \%) \\
74(42.0 \%) \\
51(29.0 \%), 3(1.7 \%) \\
122(69.3 \%)\end{array}$ \\
\hline Number of radioiodine treatment cycles & $\begin{array}{l}1,2,3,4,5,6 \\
\text { Median } \\
\text { Range }\end{array}$ & $\begin{array}{l}33,125,11^{\dagger}, 5^{\dagger}, 0,2^{\dagger} \\
2 \\
1-6\end{array}$ \\
\hline Cumulative ${ }^{131}$ I activity $(\mathrm{GBq})^{\ddagger}$ & $\begin{array}{l}\leq 3.7,3.8-7.4,>7.4 \\
\text { Median } \\
\text { Range }\end{array}$ & $\begin{array}{l}28,90,58 \\
7.4 \\
1.9-35.0\end{array}$ \\
\hline${ }^{131}$ I score & $\begin{array}{l}0,1,2,3,4 \\
\text { No scan }\end{array}$ & $\begin{array}{l}128 \text { (72.7\%), } 1 \text { (0.6\%), } 7 \text { (4.0\%), } 0 \text { (0\%), } 17 \text { (9.7\%) } \\
23 \text { (13.1\%) }\end{array}$ \\
\hline Follow-up (y) & $\begin{array}{l}\text { Median } \\
\text { Range }\end{array}$ & $\begin{array}{l}6.6 \\
1.0-32.6\end{array}$ \\
\hline Observed period (patient-years) & $\begin{array}{l}\text { Before radioiodine } \\
\text { After radioiodine }\end{array}$ & $\begin{array}{l}8,472 \\
1,421\end{array}$ \\
\hline Frequency of tooth brushing (per day) & $\begin{array}{l}1,2,3,4 \\
>4 \\
\text { No information }\end{array}$ & $\begin{array}{l}10(5.7 \%), 93(52.8 \%), 49(27.8 \%), 7(4.0 \%) \\
2(1.1 \%) \\
15(8.5 \%)\end{array}$ \\
\hline Additional dental care tools§ & $\begin{array}{l}0,1,2,3 \\
>3 \\
\text { No information }\end{array}$ & $\begin{array}{l}26(14.8 \%), 72(40.9 \%), 46(26.1 \%), 13(7.4 \%) \\
1(0.6 \%) \\
18(10.2 \%)\end{array}$ \\
\hline Additional caries prevention $\|$ & $\begin{array}{l}\text { No, yes } \\
\text { No information }\end{array}$ & $\begin{array}{l}136(77.3 \%), 19(10.8 \%) \\
21(11.9 \%)\end{array}$ \\
\hline Xerostomia before radioiodine therapy & $\begin{array}{l}\text { No, yes } \\
\text { No information }\end{array}$ & $\begin{array}{l}138(78.4 \%), 2(1.1 \%) \\
36(20.5 \%)\end{array}$ \\
\hline Caries before radioiodine therapy & $\begin{array}{l}\text { No, yes } \\
\text { No information }\end{array}$ & $\begin{array}{l}18(10.2 \%), 69(39.2) \\
89(50.6 \%)\end{array}$ \\
\hline Tooth extractions before radioiodine & $\begin{array}{l}\text { No, yes } \\
\text { No information }\end{array}$ & $\begin{array}{l}100(56.8 \%), 21(11.9 \%) \\
55(31.3 \%)\end{array}$ \\
\hline \multicolumn{3}{|c|}{$\begin{array}{l}{ }^{*} \text { One patient had received thyroidectomy in South Africa and pathologic files were unavailable. } \\
{ }^{\dagger} \text { Multiple treatment cycles }(>2) \text { were administered for reablation }(6 \text { cases) or metastatic disease (12 cases). } \\
{ }^{\ddagger} \mathrm{GBq}=\text { gigabequerels (convert values from gigabequerel to curies by dividing by } 37 \text { ). } \\
\text { \$Dental floss, tooth picks, mouth rinsing. } \\
\text { "Fluoride rail, fluoride gel, fluoridated tooth paste. } \\
{ }^{\|} \text {After written and oral invitation, the respective dentists were not willing or able to provide data. }\end{array}$} \\
\hline
\end{tabular}

activity of $7.4 \mathrm{GBq}$ (range, 1.9-35.0 GBq). The median age at first radioiodine treatment was $48.4 \mathrm{y}$ (range, 17.6-86.3 y; 8,472 patient-years before treatment). The median follow-up period was $6.6 \mathrm{y}$ (range, 1.1-32.6 y; 1,421 patient-years after treatment).

\section{Imaging}

Intratherapeutic ${ }^{131}$ I scans were available for 151 participants $(85.8 \%)$. Twenty-five cases $(16.6 \%)$ showed visible salivary gland uptake; 1 case had a score of 1,7 cases had a score of 2 , and 17 cases had a score of 4 . No elevated radioiodine uptake in the salivary glands was found in 126 cases.

\section{Oral Status}

No participant had endured sialadenitis before radioiodine. After radioiodine, 43 patients (24.4\%) showed sialadenitis, in 1 ( 25 cases), 2 (16 cases), or 3 glands ( 2 cases). Sialadenitis grade I occurred in 11 patients $(6.3 \%)$ and sialadenitis grade II occurred in 32 patients (18.2\%). Sialadenitis in $>3$ glands or grade III or grade IV sialadenitis did not occur. One-hundred twenty-two $(69.3 \%)$ participants did not experience sialadenitis; 11 participants 
(6.3\%) gave no information. Visible salivary gland uptake was an independent predictor for postradioiodine sialadenitis (odds ratio [per gland with visible radioiodine uptake]: 1.31 ; range, $1.05-1.63 ; P=0.015$; Table 2).

Two participants $(1.1 \%)$ endured xerostomia before radioiodine treatment (during 8,472 patient-years) and 78 of 176 participants $(44.3 \%)$ endured xerostomia after radioiodine treatment (during 1,421 patient-years). Grade I xerostomia was found in 46 cases, and grade II was found in 32 cases. Grade III and grade IV xerostomia did not occur. Eightyseven participants $(66.9 \%)$ did not experience xerostomia after radioiodine, 11 participants $(6.3 \%)$ gave no information. Visible salivary gland uptake (odds ratio [per affected gland]: 1.58 [1.16-2.16], $P=0.004)$, the cumulative radioiodine activity (odds ratio [per gigabequerel]: 1.15 (1.041.29), $P=0.010$ ), and sialadenitis after radioiodine (odds ratio: 2.88 (1.64-5.07), $P=0.001$; Table 2) were independent risk factors for xerostomia after radioiodine.
Through 5,652 patient-years before radioiodine treatment, caries was reported for 69 of 121 participants $(57.0 \%)$. In 949 patient-years after radioiodine treatment, new caries had developed in 59 participants $(48.8 \%)$. Caries before radioiodine treatment (\% increase: 32.2 [12.0-56.1], $P=$ $0.001)$ and after radioiodine xerostomia (\% increase: 98.8 [26.5-212], $P=0.003$; Table 2) were independent risk factors for caries after radioiodine.

Throughout 5,652 patient-years before radioiodine treatment, 54 tooth extractions had been performed in 21 of 122 patients (17.2\%) —in 12 cases for dental disease, in 8 cases for periodontal disease, and in 1 case for both indications. For the period of 949 patient-years of follow-up after radioiodine treatment, 61 tooth extractions were performed in 27 patients (22.3\%) - in 18 cases for dental disease, in 8 cases for periodontal disease, and in 1 case for both indications. Participants with tooth extractions before radioiodine treatment were at risk to undergo further extractions

TABLE 2

Risk Factors for Early $(n=176)$ and Late $(n=121)$ Endpoints

\begin{tabular}{|c|c|c|c|c|c|}
\hline Endpoint & Risk factor ${ }^{*}$ & Odds ratio unadjusted & $P$ value & Odds ratio adjusted ${ }^{\dagger}$ & $P$ value \\
\hline Sialadenitis $^{\ddagger}$ & $\begin{array}{l}\text { Age } \\
\text { Male } \\
\text { lodine activity } \\
\text { lodine score }\end{array}$ & $\begin{array}{l}0.997(0.98-1.02) \\
0.67(0.32-1.39) \\
1.03(0.96-1.10) \\
1.28(1.04-1.58)\end{array}$ & $\begin{array}{l}0.79 \\
0.28 \\
0.40 \\
0.020\end{array}$ & $\begin{array}{l}0.99(0.97-1.02) \\
0.59(0.26-1.37) \\
1.03(0.94-1.13) \\
\mathbf{1 . 3 1}(\mathbf{1 . 0 5 - 1 . 6 3 )}\end{array}$ & $\begin{array}{l}0.59 \\
0.22 \\
0.53 \\
\mathbf{0 . 0 1 5}\end{array}$ \\
\hline Xerostomia ${ }^{\ddagger}$ & $\begin{array}{l}\text { Age } \\
\text { Male } \\
\text { lodine activity } \\
\text { lodine score } \\
\text { Sialadenitis }\end{array}$ & $\begin{array}{l}0.99(0.97-1.02) \\
1.66(0.74-3.75) \\
1.11(0.98-1.25) \\
1.52(1.09-2.11) \\
2.37(1.28-4.41)\end{array}$ & $\begin{array}{l}0.55 \\
0.22 \\
0.088 \\
0.014 \\
0.006\end{array}$ & $\begin{array}{l}1.00(0.98-1.03) \\
1.79(0.92-3.48) \\
1.15(1.04-1.29) \\
1.58(1.16-2.16) \\
2.88(1.64-5.07)\end{array}$ & $\begin{array}{l}0.76 \\
0.09 \\
\mathbf{0 . 0 1 0} \\
\mathbf{0 . 0 0 4} \\
\mathbf{0 . 0 0 1}\end{array}$ \\
\hline Caries§ & $\begin{array}{l}\text { Age } \\
\text { Male } \\
\text { lodine activity } \\
\text { lodine score } \\
\text { Sialadenitis } \\
\text { Xerostomia } \\
\text { Prior caries } \\
\text { Tooth brushing }\end{array}$ & $\begin{array}{l}\% \text { increase unadjusted } \\
1.5(-0.1 \text { to } 3.2) \\
-13.1(-51.2 \text { to } 54.8) \\
-2.0(-9.6 \text { to } 6.3) \\
-3.1(-27.5 \text { to } 29.7) \\
35.9(-7.5 \text { to } 99.9) \\
82.0(10.9 \text { to } 199) \\
39.3(18.6 \text { to } 63.7) \\
10.6(-18.3 \text { to } 49.7)\end{array}$ & $\begin{array}{l}0.07 \\
0.63 \\
0.63 \\
0.83 \\
0.12 \\
0.018 \\
0.001 \\
0.52\end{array}$ & $\begin{array}{l}\text { \% increase adjusted } \\
1.4(-0.3 \text { to } 3.2) \\
-11.0(-32.7 \text { to } 82.8) \\
-3.2(-9.5 \text { to } 3.4) \\
-14.7(-33.9 \text { to } 10.1) \\
-15.6(-41.9 \text { to } 22.5) \\
98.8(26.5 \text { to } 212) \\
32.2(12.0 \text { to } 56.1) \\
-10.4(-37.5 \text { to } 28.5)\end{array}$ & $\begin{array}{l}0.12 \\
0.68 \\
0.33 \\
0.22 \\
0.37 \\
\mathbf{0 . 0 0 3} \\
\mathbf{0 . 0 0 1} \\
0.55\end{array}$ \\
\hline Tooth extraction $\S \|$ & $\begin{array}{l}\text { Age } \\
\text { Male } \\
\text { lodine activity } \\
\text { lodine score } \\
\text { Sialadenitis } \\
\text { Xerostomia } \\
\text { Prior caries } \\
\text { Date of radioiodine therapy } \\
\text { Tooth brushing }\end{array}$ & $\begin{array}{l}-1.32(-4.40,1.85) \\
-26.4(-75.0-116.5) \\
6.91(0.74-13.5) \\
-7.5(-43.8-52.4) \\
16.3(-33.9,105) \\
2.24(-58.9,154) \\
1.14(-30.6,47.3) \\
-5.46(10.3,-0.42) \\
-28.7(-64.0,41.3)\end{array}$ & $\begin{array}{l}0.41 \\
0.58 \\
0.03 \\
0.76 \\
0.60 \\
0.96 \\
0.95 \\
0.03 \\
0.33\end{array}$ & $\begin{array}{l}-0.72(-4.27,2.97) \\
-45.1(-85.4,106) \\
\mathbf{8 . 1 4}(\mathbf{1 . 0 7}, \mathbf{1 5 . 7}) \\
-1.19(-41.6,67.2) \\
-10.6(-56.2,82.3) \\
-25.7(-73.1,105) \\
7.50(-29.6,64.1) \\
-5.11(-10.9,1.02) \\
-39.6(-72.1,30.7)\end{array}$ & $\begin{array}{l}0.70 \\
0.37 \\
0.02 \\
0.96 \\
0.76 \\
0.57 \\
0.74 \\
0.10 \\
0.20\end{array}$ \\
\hline
\end{tabular}

${ }^{*}$ The respective units are as follows: age, per year; male, vs. female; iodine activity, per GBq; iodine score, per gland; sialadenitis, per gland affected; prior caries, per site; tooth brushing, times per day.

${ }^{\dagger}$ Adjusted for all other covariates in the list.

${ }^{\ddagger}$ Estimates were obtained from binomial regression models and refer to individual sites.

§Estimates were obtained from Poisson regression models and refer to individual sites.

"Number of tooth extractions after radioiodine therapy in patients without prior extractions.

Corresponding $95 \%$ confidence intervals are in parentheses. Boldface type indicates statistical significance of the respective covariate. 
after radioiodine treatment $(P=0.0005)$. In patients at risk for the first tooth extraction, the cumulative radioiodine activity was an independent risk factor ( $\%$ increase [per gigabequerel]: 8.14 [1.07, 15.7], $P=0.02$; Table 2) for undergoing a tooth extraction after radioiodine treatment. Cumulative radioiodine activities exceeding the standard activity of $7.4 \mathrm{GBq}$ induced a significantly increased risk for undergoing tooth extractions (Cox regression: $P<0.001$; Fig. 3 ).

Sensitivity analyses for all endpoints revealed no significant changes in the results of the regression models after exclusion of patients with nonavailable radioiodine scans or missing data on caries before radioiodine treatment.

\section{DISCUSSION}

Our data indicate detrimental effects of high-dose radioiodine treatment on the long-term dental health, divided into acute and long-term effects.

Acute adverse events of salivary gland irradiation in high-dose radioiodine treatment comprise sialadenitis $(7,8)$, palsy of the facial nerve, which passes through the parotid (15), taste loss (7), and oral candidiasis (16). Reducing the salivary gland dose will be crucial to reduce the rates of these events. The value of increasing salivation by sour juice and lemon candy remains elusive $(8,10)$, whereas amifostine reduces salivary gland impairment in high-dose radioiodine treatment $(10)$. Our results on the long-term consequences highlight the need to reduce initial salivary gland impairment. Furthermore, several risk factors emerged in this study-especially the scintigraphic salivary gland uptake might help in identifying patients at need for intensified follow-up.

Long-term effects of salivary gland irradiation in highdose radioiodine treatment comprise chronic sialadenitis (14), permanent taste loss (14), xerostomia (7-9), and increased salivary gland malignancies (17). Xerostomia after external irradiation increases the caries rate $(12,13)$ and, thus, saliva substitutes, sialogogues (18), water, sugarless sweets, or gum are used for secondary prevention (13). Our data indicate detrimental effects on dental health also by postradioiodine xerostomia and we observed increasing tooth extraction rates with increasing cumulative radioiodine activities. This emphasises the need for secondary prevention after high-dose radioiodine treatment, especially in patients with high cumulative radioiodine activities and postradioiodine xerostomia. Secondary preventive measures include caution with anticholinergic drugs, avoidance of dehydration, and preserving salivary gland flow with glandular massage (14).

Radioiodine has an established benefit in large thyroid malignancies, whereas its value in small papillary thyroid cancers remains elusive (19). However, an adequately powered pooled risk analysis has recently indicated an increased incidence of secondary malignancies after highdose radioiodine therapy in organs concentrating radioiodine, such as salivary glands, bladder, colon, and kidneys (17). Additionally, our data suggest detrimental effects on the long-term dental health. The growing data on benefit and adverse events might help to restrict radioiodine to patients in whom it is beneficial.

Our study has strengths and limitations. First, our analyses were sufficiently powered to obtain significant results; nevertheless, they need independent confirmation. Second, 25 patients refused to participate. However, their baseline criteria, including predictive factors such as the iodine score, did not significantly vary from the participants' baseline criteria, not indicating a specific bias. Third, we did not quantify salivary gland function by ${ }^{99 \mathrm{~m}} \mathrm{Tc}$-pertechnetate scintigraphy. However, subclinical xerostomia diagnosed by ${ }^{99 \mathrm{~m}} \mathrm{Tc}$-pertechnetate scintigraphy is found in all patients after high-dose radioiodine therapy and therefore is not predictive for clinically relevant xerostomia (10). Fourth,
FIGURE 3. Association of cumulative radioiodine activity and risk of tooth extractions after radioiodine (assessed by Cox regression).

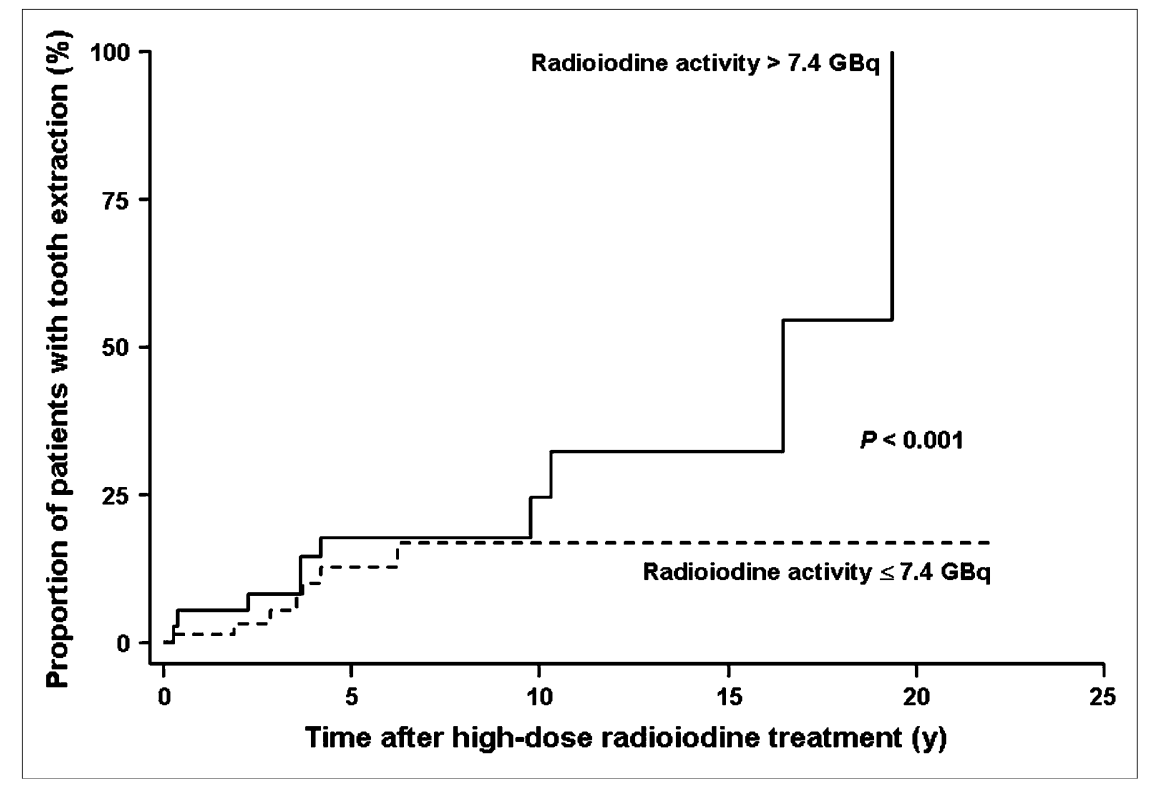


increasing cumulative radioiodine activities, but not sialadenitis or xerostomia, were predictors for postradioiodine tooth extractions. This might be due to the fact that continuous variables, in contrast to dichotomous or categoric variables, facilitate the detection of significant predictors. Finally, we were not able to define preventive measures to avoid long-term dental impairment after high-dose radioiodine treatment. The detection of adequate preventive measures remains preserved for further trials.

\section{CONCLUSION}

High-dose radioiodine treatment can impair the long-term dental health, depending on the intensity of treatment and individual radioiodine uptake within the salivary glands. Patients should be made aware of salivary gland damage before high-dose radioiodine treatment. Lifelong secondary prevention and intensified follow-up should be considered, especially in patients who have received high cumulative radioiodine activities or who have developed postradioiodine xerostomia. Further efforts should address reducing the initial salivary gland dose and exploring preventive measures to reduce long-term dental impairment.

\section{ACKNOWLEDGMENTS}

For providing patient data, we are grateful to Arato Andreas, Asal Erbin, Bachmann André, Beck Klaus, Böhringer Peter, Bolf Pavel, Borner Andreas, Bossart Markus, Brandsch Karlheinz, Brentel Elena, Bruder Hoek Almut, Brunner Hansruedi, Chevillat Marcel, De Cassan Klaus, Dvoracek Jiri, Epting Christoph, Ernst Karin, Fechtig Thilo, Felber Peter, Fischer Christoph, Frehner Gerhard, Frei Christoph, Gall Erich, Gianola Angelo, Grass Helmold, Güdel Markus, Gürtler Christian, Harr Roger, Heckmann Jörn, Heidelberger Martin, Herrlich Anna, Hersberger Urs, Hinkelbein Richard, Hoffmann Marc, Hohermuth Christian, Hongler Mario, Howald Stephan, Hunkeler Rainer, Jäger Urs, Kalla Robert, Karp Monika, Keller Markus, Kraus Josef, Küng Walter, Kupferschmid Hans-Peter, Leuenberger Martin, Loepfe Remo, Löpfe Ulrich, Lutgen Alex, Maillat Stéphane, Marti Brigitte, Mindszenty Eva, Mischler Christian, Moor Beat, Moser Nicole, Nattenmüller Erich, Olsson Anders, Oprea Niculae, Planinic Vladimir, Radics Josef, RigoGabory Margit, Scherble Karlheinz, Schöpflin Hanspeter, Schweizer Brigitte, Senn Christoph, Siegenthaler Thomas, Steenblock Zwantie, Stiffler Hans Peter, Thomann Hansruedi,
Tobler Jürg, Trzeciak Wanda, Weh Hans-Jürgen, Weidmann Renatus, Weisskopf Niklaus, Wiegand Wolfgang, Yolalan Sedat, Zaborsky Jan, Zehnder René and Zimmermann Beat. We also thank Briel Matthias, Christ-Crain Mirjam, and Rasch Helmut for their valuable comments on the manuscript.

\section{REFERENCES}

1. Schlumberger MJ. Papillary and follicular thyroid carcinoma. $N$ Engl J Med. 1998;338:297-306.

2. Vini L, Harmer C. Management of thyroid cancer. Lancet Oncol. 2002;3: 407-414.

3. Dohan O, De la Vieja A, Paroder V, et al. The sodium/iodide symporter (NIS): characterization, regulation, and medical significance. Endocr Rev. 2003;24: 48-77.

4. Kolbert KS, Pentlow KS, Pearson JR, et al. Prediction of absorbed dose to normal organs in thyroid cancer patients treated with ${ }^{131} \mathrm{I}$ by use of ${ }^{124} \mathrm{I}$ PET and 3-dimensional internal dosimetry software. J Nucl Med. 2007;48:143-149.

5. Stephens LC, Schultheiss TE, Price RE, Ang KK, Peters LJ. Radiation apoptosis of serous acinar cells of salivary and lacrimal glands. Cancer. 1991;67:15391543 .

6. Sherman SI. Thyroid carcinoma. Lancet. 2003;361:501-511.

7. Alexander C, Bader JB, Schaefer A, Finke C, Kirsch CM. Intermediate and longterm side effects of high-dose radioiodine therapy for thyroid carcinoma. $\mathrm{J} \mathrm{Nucl}$ Med. 1998;39:1551-1554.

8. Nakada K, Ishibashi T, Takei T, et al. Does lemon candy decrease salivary gland damage after radioiodine therapy for thyroid cancer? J Nucl Med. 2005;46: 261-266.

9. Solans R, Bosch JA, Galofre P, et al. Salivary and lacrimal gland dysfunction (sicca syndrome) after radioiodine therapy. J Nucl Med. 2001;42:738-743.

10. Bohuslavizki KH, Klutmann S, Brenner W, Mester J, Henze E, Clausen M. Salivary gland protection by amifostine in high-dose radioiodine treatment: results of a double-blind placebo-controlled study. J Clin Oncol. 1998;16:35423549.

11. Maier H, Bihl H. Effect of radioactive iodine therapy on parotid gland function. Acta Otolaryngol. 1987;103:318-324.

12. Kielbassa AM, Hinkelbein W, Hellwig E, Meyer-Luckel H. Radiation-related damage to dentition. Lancet Oncol. 2006;7:326-335.

13. Stone HB, Coleman CN, Anscher MS, McBride WH. Effects of radiation on normal tissue: consequences and mechanisms. Lancet Oncol. 2003;4:529-536.

14. Mandel SJ, Mandel L. Radioactive iodine and the salivary glands. Thyroid. 2003;13:265-271.

15. Levenson D, Gulec S, Sonenberg M, Lai E, Goldsmith SJ, Larson SM. Peripheral facial nerve palsy after high-dose radioiodine therapy in patients with papillary thyroid carcinoma. Ann Intern Med. 1994;120:576-578.

16. Bushnell DL, Boles MA, Kaufman GE, Wadas MA, Barnes WE. Complications, sequela and dosimetry of iodine-131 therapy for thyroid carcinoma. J Nucl Med. 1992;33:2214-2221.

17. Rubino C, de Vathaire F, Dottorini ME, et al. Second primary malignancies in thyroid cancer patients. Br J Cancer. 2003;89:1638-1644.

18. LeVeque FG, Montgomery M, Potter D, et al. A multicenter, randomized, double-blind, placebo-controlled, dose-titration study of oral pilocarpine for treatment of radiation-induced xerostomia in head and neck cancer patients. $J$ Clin Oncol. 1993;11:1124-1131.

19. Cooper DS, Doherty GM, Haugen BR, et al. Management guidelines for patients with thyroid nodules and differentiated thyroid cancer. Thyroid. 2006;16: $109-142$. 